Polymer Journal, Vol. 9, No. 6, pp 641-648 (1977)

\title{
Dielectric Dispersion of Polypeptide Solutions. III. Conformation and Dipole Moment of Copolypeptides of $\gamma$-Benzyl L-Glutamate and L-Alanine in $m$-Cresol
}

\author{
Noboru Nishioka, ${ }^{*}$ Hiroko Mishima, and Akio Teramoto \\ Department of Polymer Science, Osaka University, \\ Toyonaka, Osaka 560, Japan.
}

(Received August 2, 1977)

\begin{abstract}
Block and random copolypeptides of $\gamma$-benzyl L-glutamate and $L$ alanine of narrow molecular weight distribution were synthesized by successive polymerization of the corresponding $N$-carboxy $\alpha$-amino acid anhydrides with initiation by $n$-butylamine. Optical rotatory dispersion data show that the copolypeptides studied are essentially $\alpha$-helical in $m$-cresol in a temperature range between 10 and $50^{\circ} \mathrm{C}$. Dielectric dispersion and viscosity data for $m$-cresol solutions indicate that the copolypeptides have a rodlike molecular shape. The dielectric dispersion data in $m$-cresol as a function of copolymer composition gave $6.4 \pm 0.1 \mathrm{D}$ for the monomeric dipole moment of L-alanine residue. This value is larger than those reported for other polypeptides with polar side chains, and suggests that the side chain dipoles on the average run antiparallel to the backbone dipoles. For polypeptides with polar side chains, the monomeric dipole moment was found to increase with the length of the side chain. This is ascribed to the increased rotational freedom of the longer side chain, which tends to reduce the side chain contribution to the total dipole moment.

KEY WORDS Copolypeptide / Poly( $\gamma$-benzyl L-glutamate) / Poly(Lalanine) / $\alpha$-Helix / Dielectric Dispersion / Dipole Moment / Optical Rotatory Dispersion / Intrinsic Viscosity /
\end{abstract}

Polypeptides carry permanent dipoles on the planar $\mathrm{CO}-\mathrm{NH}$ groups of the backbone chain and generally on some atomic groups of the side chain. Because of the vector nature of dipole moment, dielectric dispersion measurements provide information about the mean-square dipole moment averaged over all possible conformations of the chain backbone and all accessible orientations of the side chain. ${ }^{1-6}$ In the $\alpha$-helical conformation, a polypeptide molecule should form a large permanent dipole, since all the dipoles on the backbone chain are virtually parallel to the helix axis, whereas the side chain dipoles are presumably in random orientation., ${ }^{1,2}$ One may be able to obtain information about the side chain orientation from the difference between the overall dipole moment and the backbone dipole moment if the latter can be estimated separately. ${ }^{1-4}$

* Present Address: Osaka Electro-Communication University, Neyagawa, Osaka 572, Japan.
Wada $^{1,2}$ proposed two methods for evaluating the backbone dipole moment: in one of them, DL random copolymers of $\gamma$-benzyl glutamates were used, and in the other, random copolymers of $\gamma$-benzyl L-glutamate (BLG) and L-alanine (LA) were examined. However, both involve rather lengthy extrapolation procedures with respect to copolymer composition, so that the accuracy of the derived values is open to question. One of the aims of the present study is a direct evaluation of the backbone dipole moment with the use of BLG-LA copolymers.

Poly(L-alanine) (PLA) has no polar side chain, and hence it is suitable for the evaluation of the backbone dipole moment. ${ }^{2}$ However, it is soluble neither in ordinary organic liquids nor in aqueous media. Hence its conformation has been examined mostly in such particular solvents as dichloroacetic acid (DCA), trifluoroacetic acid (TFA), hexafluoro-2-propanol (HFIP), and mixtures containing these organic acids. ${ }^{7-10}$ This 
solubility problem can be resolved in part by the "block copolymer technique," which utilizes a non-polar polypeptide sandwiched between blocks of hydrophilic D,L-copolypeptide..$^{11-16}$ We employed a similar idea in the present study, in which PLA flanked with PBLG blocks was chosen to examine the conformation of PLA in organic solvents. PBLG dissolves in many organic liquids, so that it is appropriate for solubilizing the central PLA block.

\section{EXPERIMENTAL}

\section{Polypeptide Samples}

$N$-Carboxy anhydride of $\gamma$-benzyl L-glutamate (BLG-NCA) was prepared according to the method of Blout and Karlson. ${ }^{17} \quad \mathrm{~N}$-Carboxy anhydride of L-alanine (LA-NCA) was prepared in a similar way, with isopropyl ether used as the crystallization solvent. Triblock copolypeptides of the type BLG-LA-BLG were synthesized by successive polymerization of BLGNCA and LA-NCA, following a procedure similar to those employed in our previous studies. ${ }^{18,19}$ First, BLG-NCA was polymerized in dimethylformamide (DMF) with $n$-butylamine as the initiator, and an aliquot of the polymerization mixture was used to initiate poly- merization of LA-NCA dissolved in DMF or dichloromethane (DCM). To this polymerization mixture was added a weighed amount of BLG-NCA in DMF or DCM to effect the third stage polymerization. Finally the polymerization mixture was poured into a large volume of methanol and the precipitated polymer was collected. Polymerization mixtures with larger LA-NCA contents became turbid after addition of LA-NCA at the second stage. The mixtures became clearer by dilution with DCM, but remained slightly turbid. This was probably because the PLA chains were apt to form aggregates due to their poor solubility. However, even in such cases, the amino acid residue at the growing end of the preformed polymer seemed to retain an activity for polymerization, because $\mathrm{CO}_{2}$ gas started evolving immediately after the addition of BLG-NCA to the turbid solution. Diblock and random copolymers were similarly synthesized with DMF as solvent. Table I summarizes the preparative data.

Samples GAG-6, GAG-7, GA-11, and GA-12 were dispersed in DMF, and the insoluble parts were collected, dispersed in dioxane, and freezedried. The soluble parts, which presumably contained only a slight amount of polymers of low molecular weight, were discarded. Random

Table I. Preparative data for BLG-LA copolypeptides

\begin{tabular}{|c|c|c|c|c|c|c|}
\hline Sample code & {$[\mathbf{A}]_{0} /[\mathbf{I}]_{0}$} & $\begin{array}{c}{[\eta], \mathrm{c}} \\
\mathrm{d} l / \mathrm{g}\end{array}$ & $\bar{N}_{v}^{\mathrm{d}}$ & $\begin{array}{l}\text { Yield, } \\
\%\end{array}$ & $\underset{\mathrm{mol} \%}{\mathrm{LA}}$ & $\begin{array}{c}\text { Polymerization } \\
\text { solvent }\end{array}$ \\
\hline GAG- 1 & $30-5-30$ & 0.157 & 62 & 87 & 10.6 & DMF \\
\hline$G A G-2$ & $30-10-30$ & 0.165 & 67 & 84 & 11.8 & DMF \\
\hline GAG- 3 & $30-20-30$ & 0.176 & 74 & 84 & 26.2 & DMF \\
\hline GAG- 4 & $50-30-50$ & 0.251 & 115 & 89 & 22.7 & $\mathrm{DMF}+\mathrm{DCM}$ \\
\hline$G A G-5$ & $50-50-50$ & 0.251 & 115 & 80 & 36.5 & $\mathrm{DMF}+\mathrm{DCM}$ \\
\hline GAG- 6 & $50-75-50$ & 0.350 & 175 & 92 & 45.6 & $\mathrm{DMF}+\mathrm{DCM}$ \\
\hline GAG- 7 & $50-100-50$ & 0.404 & 210 & 94 & 51.8 & $\mathrm{DMF}+\mathrm{DCM}$ \\
\hline GAG- $8^{a}$ & $60: 10$ & 0.172 & 72 & 87 & 14.1 & $\mathrm{DMF}$ \\
\hline$G A G-9^{a}$ & $60: 20$ & 0.166 & 67 & 88 & 24.4 & DMF \\
\hline GAG-10a & $100: 50$ & 0.197 & 85 & 84 & 35.0 & DMF \\
\hline$G A-11^{b}$ & $100-30$ & 0.262 & 120 & 87 & 23.6 & $\mathrm{DMF}$ \\
\hline $\mathrm{GA}-12^{\mathrm{b}}$ & $100-50$ & 0.274 & 130 & 89 & 30.2 & DMF \\
\hline
\end{tabular}

a Random copolypeptides.

b Diblock copolypeptides.

c Determined in DCA at $25^{\circ} \mathrm{C}$.

d Estimated from the intrinsic viscosities in DCA at $25^{\circ} \mathrm{C}$ using the empirical relation shown in Figure 5 .

e Estimated by elemental analysis. 
Table II. Molecular weights of BLG-LA copolypeptides in DMF and HFIP at $25^{\circ} \mathrm{C}$

\begin{tabular}{lcrrrr}
\hline $\begin{array}{c}\text { Sample } \\
\text { code }\end{array}$ & $\bar{M}_{w} \times 10^{-4} \begin{array}{c}A_{2} \times 10^{4},^{\mathrm{e}} \\
\mathrm{mol} \mathrm{m} / \mathrm{g}^{2}\end{array}$ & $\bar{N}_{w}$ & \multicolumn{1}{c}{$\begin{array}{c}\mathrm{LA}, \\
\mathrm{mol} \% \mathrm{c}\end{array}$} & $\bar{N}_{w} / \bar{N}_{n}{ }^{\mathrm{d}}$ \\
\hline GAG- 1 & $1.34^{\mathrm{a}}$ & 7.6 & 66.3 & 11.3 & 1.03 \\
GAG- 2 & $1.39^{\mathrm{a}}$ & 8.4 & 69.1 & 12.2 & 1.03 \\
GAG- 3 & 1.33 & 10.0 & 73.3 & 25.5 & 1.04 \\
GAG- 4 & 2.44 & 6.7 & 131.0 & 22.2 & 1.04 \\
GAG- 5 & 1.89 & 10.5 & 116.4 & 38.4 & 1.04 \\
GAG- 60 & 2.38 & 8.7 & 154.4 & 43.9 & 1.09 \\
GAG- 70 & 2.26 & 10.3 & 154.1 & 48.9 & 1.10 \\
GAG- 82 & $1.17^{\mathrm{a}}$ & 8.6 & 59.5 & 15.8 & 1.04 \\
GAG- 92 & $1.20^{\mathrm{a}}$ & 8.8 & 64.1 & 21.7 & 1.02 \\
GAG-102 & $1.73^{\mathrm{a}}$ & 5.4 & 101.3 & 32.7 & 1.04 \\
GA-110 & $2.26^{\mathrm{b}}$ & - & 125 & 25.4 & 1.06 \\
GA-120 & $2.25^{\mathrm{b}}$ & - & 135 & 35.9 & 1.06 \\
\hline
\end{tabular}

a Determined in DMF.

$b$ Viscosity-average molecular weights calculated from intrinsic viscosities by the empirical relation shown in Figure 5.

c Estimated by elemental analysis and NMR spectra.

d Determined by Bur's method. ${ }^{22}$

e $A_{2}$, second virial coefficient.

copolymers GAG-8, GAG-9, and GAG-10 were fractionated by the column elution method with mixtures of DCM and methanol as eluent, and appropriate middle fractions were selected for physical measurements. Other samples were used without fractionation. Amino acid compositions of the copolypeptides were determined by elemental analysis and nuclear magnetic resonance (NMR). NMR spectra of TFA solutions recorded on a Varian $\mathrm{XL}-100$ spectrometer were analyzed in terms of the integrated area for the alanine $\mathrm{CH}_{3}$ peak and that of the $\gamma-\mathrm{CH}_{2}$ peak of BLG. ${ }^{16}$ Solubility tests indicated that all the samples were soluble in DCA, TFA, HFIP, and $m$-cresol and that samples with high LA contents were insoluble in DMF, DCM, and dioxane. Sedimentation equilibrium experiments were performed to determine weightaverage molecular weights, with either DMF or HFIP as solvent. The results are given in Table II. One can observe in Tables I and II that the average degrees of polymerization of the samples are approximately equal to the NCA-initiator mole ratios used in their polymerization. From our experience with primary amine-initiated polymerization of $\mathrm{NCA},{ }^{18-20}$ this fact may be taken to imply that these polymer samples were relatively homogeneous with respect to molecular weight and composition. Bur $^{21}$ has proposed a semi-empirical method for estimating the polydispersity index $\bar{N}_{w} / \bar{N}_{n}$ for a fraction of rodlike molecules, which makes use of dielectric loss data of the fraction in solution. The last column of Table II lists the values of $\bar{N}_{w} / \bar{N}_{n}$ estimated by Bur's method, which scatter between 1.02 and 1.11. These findings, though not to be taken too much at face value, conform to the conclusions deduced above from the preparative data. Bradbury, et al., ${ }^{16}$ synthesized the same type of block copolypeptides and studied their conformational transformation by optical rotatory dispersion (ORD) and NMR. These authors have given no information about the homogeneity of the samples synthesized.

\section{Optical Rotatory Dispersion}

ORD curves were measured on a JASCO ORD/UV-5 recording spectropolarimeter over a wavelength range between 300 and $600 \mathrm{~nm}$ and analyzed in terms of the Moffitt-Yang equation with $\lambda_{0}=212 \mathrm{~nm}$ to evaluate the Moffitt parameter $b_{0}$; the data were corrected for the dispersion of refractive index of the solvent used.

\section{Dielectric Dispersion}

Dielectric dispersions of $m$-cresol solutions were measured over the range of frequency between $250 \mathrm{~Hz}$ and $2 \mathrm{MHz}$ according to the procedure described elsewhere. ${ }^{20}$ The data for each sample were taken at a single concentration of $0.4-0.5 \mathrm{wt} \%$ and extrapolation to infinite dilution was not attempted. This was because preliminary experiments revealed no concentration effect on dielectric properties within the concentrations and molecular weights treated here.

\section{EXPERIMENTAL RESULTS}

\section{Optical Rotatory Dispersion}

Table III summarizes values of the Moffitt parameter $b_{0}$ obtained for $m$-cresol solutions. It is seen that for any sample the magnitude of $b_{0}$ decreases gradually with increasing temperature. This trend is opposite to what would be expected from the dependence of $b_{0}$ on the refractive index of solvent. ${ }^{23}$ Some polypeptides are known to exhibit a similar temperature dependence of $b_{0}$ in helix-supporting solvents, 
Table III. Moffitt parameters for BLG-LA copolypeptides in $m$-cresol

\begin{tabular}{lcccc}
\hline & \multicolumn{4}{c}{$-b_{0}$} \\
\hline & $10^{\circ} \mathrm{C}$ & $25^{\circ} \mathrm{C}$ & $40^{\circ} \mathrm{C}$ & $50^{\circ} \mathrm{C}$ \\
\hline GAG- 1 & 564 & 530 & 510 & 506 \\
GAG- 2 & 592 & 546 & 530 & 520 \\
GAG- 3 & 560 & 526 & 510 & 500 \\
GAG- 4 & 578 & 550 & 526 & 524 \\
GAG- 5 & 550 & 516 & 506 & 504 \\
GAG- 60 & 564 & 538 & 506 & 498 \\
GAG- 70 & 556 & 534 & 512 & 508 \\
GAG- 82 & 534 & 508 & 496 & 482 \\
GAG- 92 & 526 & 498 & 478 & 476 \\
GAG-102 & 514 & 488 & 476 & 466 \\
GA-110 & 569 & 564 & 534 & 533 \\
GA-120 & 559 & 531 & 513 & 496 \\
\hline
\end{tabular}

without accompanying a detectable conformational transition. ${ }^{24,25}$

For most polypeptides in the right-handed $\alpha$ helical conformation, $b_{0}$ is reported to be in the range between -600 and $-700 .^{26,27}$ Thus it follows from the $b_{0}$ data in Table III that the copolypeptides were not perfectly helical under the solvent conditions studied. It may be worthwhile to compare this conclusion with the findings of Matsumoto and Teramoto ${ }^{25}$ that the $b_{0}$ of PBLG in a helix-supporting solvent $m$-cresol depends significantly on molecular weight. Their data may be interpolated to give values of $b_{0}$ between -540 and -580 for PBLG samples with the same degrees of polymerization as the copolypeptides treated here. Values of $b_{0}$ for PLA in the helical conformation are reported to be about -600 in aqueous solutions and somewhat larger than this is non-aqueous solutions. ${ }^{12}$ Bradbury, et al. ${ }^{16}$ have concluded from a comparison of ORD and NMR data that $b_{0}$ can be a reliable measure of helicity for PLA. From these findings, together with the $b_{0}$ data in Table III, one may conclude that the conformation of the copolypeptides is essentially helical in $m$-cresol in the temperature range from 10 and $50^{\circ} \mathrm{C}$ and that the imperfect helix formation is ascribable to the finite molecular weights of the samples.

Dielectric Dispersion

Figure 1 shows Cole-Cole plots for sample GAG-10 (unfractionated) and GAG-102 (frac- tionated) in $m$-cresol at $25^{\circ} \mathrm{C}$, in which $\Delta \varepsilon^{\prime}$ and $\Delta \varepsilon^{\prime \prime}$ are the dielectric increment and dielectric loss factor associated with the solute. The data points are seen to fall on semicircles whose centers are located near $\Delta \varepsilon^{\prime}$ axis. The plot for the fractionated sample more closely resembles the Debye dispersion than does that for the unfractionated one, which implies that the former is more homogeneous in molecular weight than the latter. Figure 2 compares Cole-Cole plots for three unfractionated samples. These and similar data for other samples indicate that even the unfractionated samples are relatively homo-

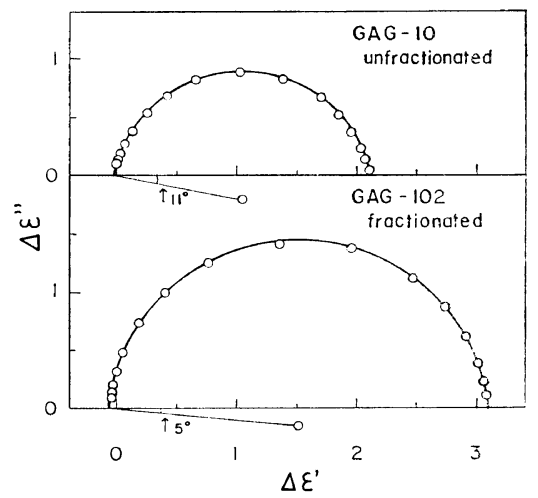

Figure 1. Cole-Cole plots for sample GAG-10 (unfractionated) and sample GAG-102 (fractionated) in $m$-cresol at $25^{\circ} \mathrm{C}$.

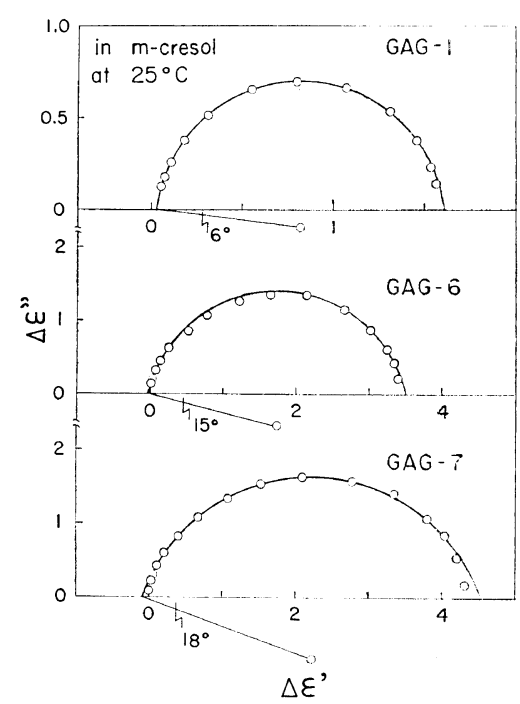

Figure 2. Cole-Cole plots for samples GAG-1, GAG-6, and GAG-7 in $m$-cresol at $25^{\circ} \mathrm{C}$. 
Dielectric Dispersion of Polypeptide Solutions

Table IV. Dielectric dispersion data for BLG-LA copolypeptides in $m$-cresol

\begin{tabular}{lcccccccc}
\hline & & \multicolumn{3}{c}{$\left\langle\mu^{2}\right\rangle^{1 / 2}, \mathrm{D}$} & \multicolumn{3}{c}{$\tau T / \eta_{0} \times 10^{3}$, sec deg/poise } \\
\cline { 5 - 9 } Sample code & $15^{\circ} \mathrm{C}$ & $25^{\circ} \mathrm{C}$ & $40^{\circ} \mathrm{C}$ & $50^{\circ} \mathrm{C}$ & $15^{\circ} \mathrm{C}$ & $25^{\circ} \mathrm{C}$ & $40^{\circ} \mathrm{C}$ & $50^{\circ} \mathrm{C}$ \\
\hline GAG- 1 & 324 & 328 & 323 & 322 & 4.10 & 3.90 & 3.76 & 3.58 \\
GAG- 2 & 337 & 341 & 341 & 343 & 4.43 & 4.20 & 4.10 & 3.93 \\
GAG- 3 & 373 & 375 & 376 & 369 & 5.21 & 5.10 & 4.79 & 4.72 \\
GAG- 4 & 640 & 649 & 648 & 646 & 19.1 & 18.3 & 17.4 & 16.8 \\
GAG- 5 & 604 & 608 & 608 & 615 & 19.1 & 18.7 & 16.8 & 16.7 \\
GAG- 60 & 820 & 831 & 832 & 816 & 40.2 & 39.9 & 37.1 & 34.6 \\
GAG- 70 & 855 & 861 & 860 & 858 & 53.5 & 52.5 & 50.0 & 50.7 \\
GAG- 82 & 292 & 292 & 296 & 295 & 3.38 & 3.29 & 3.15 & 3.11 \\
GAG- 92 & 304 & 301 & 309 & 304 & 3.89 & 3.91 & 3.42 & 3.50 \\
GAG-102 & 539 & 534 & 523 & 521 & 11.3 & 10.7 & 9.53 & 9.09 \\
GA-110 & 657 & 659 & 662 & 670 & 26.2 & 25.1 & 23.8 & 22.7 \\
GA-120 & 710 & 721 & 721 & 712 & 29.2 & 29.3 & 26.9 & 26.1 \\
\hline
\end{tabular}

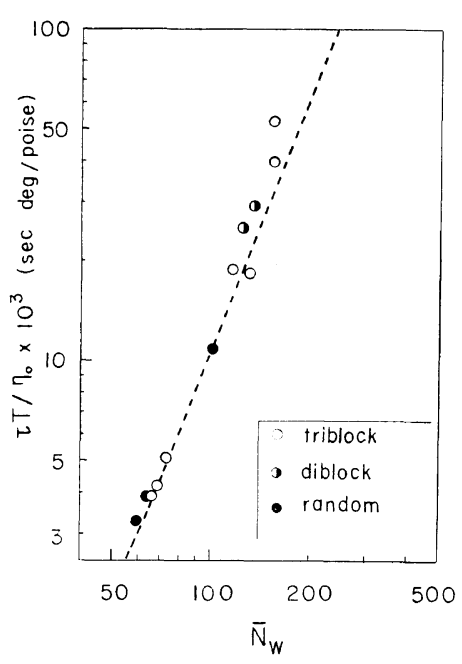

Figure 3. Double logarithmic plot of $\tau T / \gamma_{0} v s . \bar{N}_{w}$ for BLG-LA copolypeptides in $m$-cresol at $25^{\circ} \mathrm{C}$. The dashed line denotes the data for straight rod PBLG. ${ }^{20}$

geneous with respect to molecular weight. Our previous experience with $\mathrm{PBLG}^{20}$ suggests that the polydispersity index $\bar{N}_{w} / \bar{N}_{n}$ may be about 1.1 for most of the samples used for the present physical measurements and somewhat larger than this for GAG-6 and GAG-7 which contained a large fraction of LA residue. This is consistent with the estimate of $\bar{N}_{w} / \bar{N}_{n}$ by Bur's method $^{22}$ (see Table II).

The mean rotational relaxation time $\tau$ was estimated from the frequency $f_{\mathrm{c}}$ corresponding to the crest of the Cole-Cole plot by $\tau=\left(2 \pi f_{\mathrm{c}}\right)^{-1}$ and the root-mean-square dipole moment $\bar{\mu}=$ $\left\langle\mu^{2}\right\rangle^{1 / 2}$ was calculated from the static dielectric increment (equal to the segment cut out of the horizontal axis by the circle) by the ApplequistMahr equation. ${ }^{19-21,28}$ A summary of the numerical results is presented in Table IV. It is seen that both $\tau$ and $\bar{\mu}$ vary only slightly with temperature in the range examined. These features conform to the above-mentioned conclusion from the ORD data that no conformational transition occurs under the solvent conditions studied.

Figure 3 shows the molecular weight dependence of the mean rotational relaxation time corrected for the solvent viscosity $\eta_{0}$ and temperature $T$. The dashed line here denotes the values of Matsumoto, et al., ${ }^{20}$ for PBLG in helix-supporting solvents. The data points for different copolymer type and composition follow closely the PBLG curve which has a slope of 2.6. Thus it appears that the molecular shape of the copolypeptides is a straight rod, and this is consistent with the finding by ORD that the molecular conformation is essentially helical.

For a helical copolypeptide assuming the shape of a straight rod, the mean dipole moment $\bar{\mu}$ may be expressed by an algebraic sum of the contributions from the constituent amino acid residues. Each contribution is proportional to the number of the corresponding residues in the molecule. Assuming that a certain fixed number of residues at each chain end, which are assumed to be independent of the total chain length, are 
not involved in the helical sequence, one can write for helical BLG-LA copolymers

$$
\bar{\mu}-\mu_{\mathrm{G}} \bar{N}_{\mathrm{G}}=\left(\bar{\mu}^{*}-\mu_{\mathrm{G}} \bar{N}_{\mathrm{G}}{ }^{*}-\mu_{\mathrm{A}} \bar{N}_{\mathrm{A}}{ }^{*}\right)+\mu_{\mathrm{A}} \bar{N}_{\mathrm{A}}
$$

where $\mu_{\mathrm{A}}$ and $\mu_{\mathrm{G}}$ are the monomeric dipole moments along the helix axis of LA and BLG, respectively, and $\bar{N}_{\mathrm{A}}$ and $\bar{N}_{\mathrm{G}}$ are the numbers of LA and BLG residues in the molecules, respectively. The quantities with an asterisk are referred to an arbitrarily chosen reference sample.

Figure 4 shows a plot of $\left(\bar{\mu}-\mu_{G} \bar{N}_{G}\right)$ against $\bar{N}_{\mathrm{A}}$ for LA-BLG copolypeptides in $m$-cresol at $25^{\circ} \mathrm{C}$, where $\mu_{G}=4.7 \mathrm{D}$ obtained by Matsumoto, et al. ${ }^{20}$ has been used. The prediction of eq 1 is well obeyed by the data points, and the straight line drawn gives a value of $6.4 \pm 0.1 \mathrm{D}$ for $\mu_{\Delta}$. The small ordinate intercept of the line tells that the contribution from the unfolded terminal residues is quite small.

Figure 5 shows double logarithmic plots of intrinsic viscosity $v s$. degree of polymerization for $m$-cresol and DCA solutions, where the two dashed lines represent the reported [ $\eta$ ] for PBLG in DCA and DMF. ${ }^{18,29,30}$ For most polypeptides, DCA is a helix-breaking solvent, whereas DMF is a typical helix-supporting solvent. ${ }^{30}$ Thus the PBLG data in Figure 5 indicate that in the range of small $\bar{N}_{w},[\eta]$ in a helix-supporting solvent is smaller than that in a helixbreaking solvent. One also observes in Figure 5 that the $[\eta]$ in $m$-cresol is smaller than that in DCA for any sample except samples GAG-60, GAG-70. These results are compatible with the conclusion from ORD data that the molecular

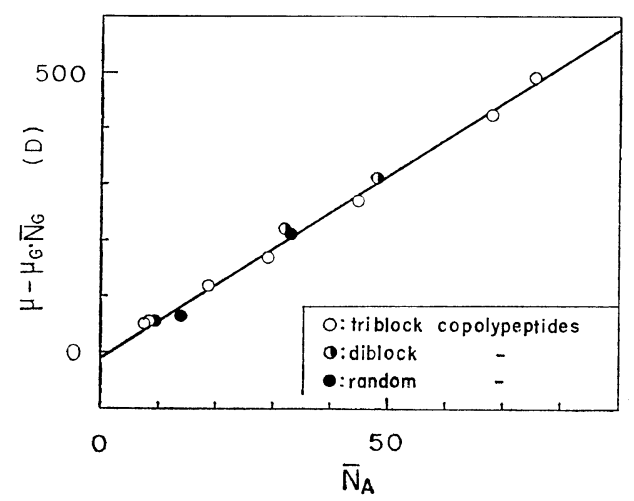

Figure 4. Plot of $\left(\bar{\mu}-\mu_{\mathrm{G}} \bar{N}_{\mathrm{G}}\right)$ vs. $\bar{N}_{\mathrm{A}}$ for BLG-LA copolypeptides in $m$-cresol at $25^{\circ} \mathrm{C}$.

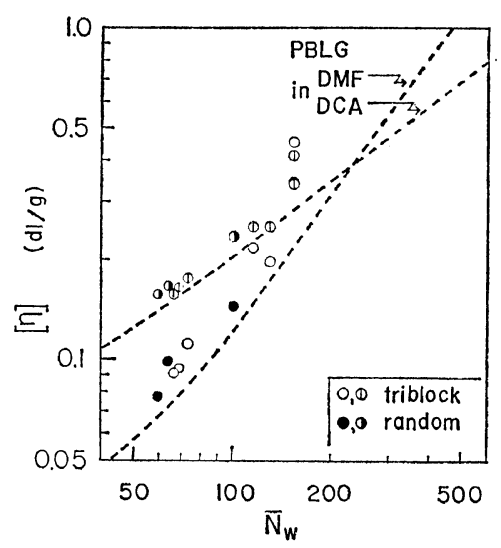

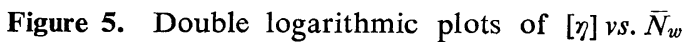
for BLG-LA copolypeptides in DCA and $m$-cresol at $25^{\circ} \mathrm{C}$ : Data in DCA, (1), ( ) data in $m$-cresol, $(\mathrm{O}, \mathrm{O})$.

conformation is $\alpha$-helical in $m$-cresol and randomly coiled in DCA. The $[\eta]$ of the samples with high LA contents, i.e., GAG-60 and GAG70 , exhibit no dependence on solvent. This is probably because the molecular conformation cannot be completely randomly coiled in DCA due to the remarkable stability of the PLA helix.

\section{DISCUSSION}

When a polypeptide molecule takes up a rigid $\alpha$-helical conformation, the backbone dipoles are arranged almost parallel to the helix axis, whereas the side chain dipoles may undergo thermal fluctuations. Determination of the dipole moments of helix residues $\mu_{\mathrm{h}}$ is thus expected to provide information about the orientation of the side chain dipoles relative to the helix axis. ${ }^{1-6}$ Experimentally, $\mu_{\mathrm{h}}$ is determined by the $\bar{\mu} / \bar{N}$, where $\bar{N}$ is the average degree of polymerization of the sample. The following criterions must be tested for an accurate estimate of $\mu_{\mathrm{h}}$.

(1) Molecular weights (or $\bar{N}$ ) must be obtained by some absolute means.

(2) Samples should be as homogeneous as possible with respect to molecular weight.

(3) Solute molecules should be molecularly dispersed in the solvent used. Polypeptide molecules are apt to aggregate themselves especially in helix-supporting solvents, and this fact seriously affects their dielectric behavior..$^{31-34}$ In 
Dielectric Dispersion of Polypeptide Solutions

Table V. Comparison of monomeric dipole moments

\begin{tabular}{|c|c|c|c|}
\hline \multirow{2}{*}{ Polypeptide } & \multirow{2}{*}{ Side chain } & \multicolumn{2}{|c|}{$\mu_{\mathrm{h}}, \mathrm{D}$} \\
\hline & & Our data ${ }^{a}$ & Wada's data ${ }^{2}$ \\
\hline PLA & $-\mathrm{CH}_{3}$ & 6.4 & 6.6 \\
\hline PBLA $^{b}$ & $-\mathrm{CH}_{2}-\mathrm{COO}-\mathrm{C}_{7} \mathrm{H}_{7}$ & 4.6 & 3.0 \\
\hline PBLG & $-\left(\mathrm{CH}_{2}\right)_{2}-\mathrm{COO}-\mathrm{C}_{7} \mathrm{H}_{7}$ & 4.7 & 3.4 \\
\hline $\mathrm{PCBL}^{\mathrm{c}}$ & $-\left(\mathrm{CH}_{2}\right)_{4}-\mathrm{NH}-\mathrm{COO}-\mathrm{C}_{7} \mathrm{H}_{7}$ & $5.4-6.2$ & - \\
\hline $\mathrm{PBDLG}^{\mathrm{d}}$ & $-\left(\mathrm{CH}_{2}\right)_{2}-\mathrm{COO}-\mathrm{C}_{7} \mathrm{H}_{7}$ & - & 6.0 \\
\hline \multicolumn{4}{|c|}{$\begin{array}{l}\text { a Data obtained in our laboratory: PLA, this work; PBLA, Saruta, } \\
\text { Omura, et al., }{ }^{21} \text { and Nishioka, et al.;19 PBLG, Matsumoto, et al. }{ }^{20} \\
\text { b Poly( } \beta \text {-benzyl L-aspartate). } \\
\text { c Poly( }(- \text {-carbobenzoxy L-lysine). } \\
\text { d Random copolypeptide of } \gamma \text {-benzyl L-glutamate and D-glutamate. }\end{array}$} \\
\hline
\end{tabular}

this respect, $m$-cresol seems to be the most appropriate solvent. ${ }^{20,35}$

(4) Samples should preferably have $\bar{N}$ approximately in the range from $60-1000$. Those with $\bar{N}$ exceeding this range gain flexibility even in helix-supporting solvents, ${ }^{20,35}$ while those with $\bar{N}$ below 60 may not be completely helical. ${ }^{25}$

Although a wealth of dielectric dispersion data is available for various helical polypeptides, ${ }^{1-6,31-35}$ many of them do not necessarily satisfy all of the above criterions. For example, some data are suspected of aggregation ${ }^{5}$ and other data give a clear sign of chain flexibility. ${ }^{32-35}$ Data without absolute molecular weights ${ }^{5,34}$ may not be relevant for quantitative discussion. Table $V$ summarizes our recent data for $\mu_{\mathrm{h}}$ which have been collected carefully to meet the above criterions. In the same table are also included the values derived by Wada. ${ }^{2}$ For each sample Wada's $\mu_{\mathrm{h}}$ value is consistently lower than ours. This is due in part to the fact that different equations have been used to estimate the dipole moments from dielectric data; the ratio of the two $\mu_{\mathrm{h}}$ values amounts to a maximum factor of $(3 / 2)^{1 / 2}$ Furthermore, Wada gave no absolute molecular weight except for the PBLG.

PLA has no polar side chain, and hence its $\mu_{\mathrm{n}}$ is taken to represent the backbone dipole moment. ${ }^{2}$ It is seen in Table $\mathrm{V}$ that the $\mu_{\mathrm{h}}$ for PLA is the largest of all and that $\mu_{\mathrm{h}}$ increases with increasing side chain length. These results confirm Wada's finding. Wada concluded from his findings that for a helical polypeptide with a polar side chain, the side chain dipoles are directed more or less antiparallel with the backbone dipoles, thus reducing the total dipole moment of the molecule. This explanation is compatible with the molecular model for the side chain of PBLG in the solid state proposed by Tsuboi $^{37}$ on the basis of infrared dichroic spectra of oriented films, although such a conformation is not likely to be held rigidly in solution.

As the side chain becomes longer, the side chain dipoles may become more randomly oriented because of a decreased dipole interaction between the backbone and the side chain. This idea explains the observed fact that $\mu_{\mathrm{h}}$ increases progressively with the length of the side chain. However, Bradbury, et al. ${ }^{38}$ have concluded from the NMR shifts of the $\beta$-methylene protons of PBLG and PBLA that the side chains of these polypeptides in helix-forming solvents had no specific orientation. Although we have no definitive explanation for these different conclusions, it seems likely that the NMR and dielectric data give different conformational averages. Erenrich and Scheraga $^{6}$ found from dielectric dispersion measurements that $\mu_{\mathrm{h}}$ in ethylene dichloride and DCM were about 3.9 D for PBLA and its chlorophenyl derivatives and $4.11 \mathrm{D}$ for PBLG and regarded that these $\mu_{\mathrm{h}}$ values were in substantial agreement with each other within experimental uncertainty. From a comparison with the values calculated in terms of a rotational isomeric state model, they concluded that the side chain would have no regular 


\section{N. Nishioka, H. Mishima, and A. Teramoto}

conformation. However, the data in Table V is at variance with this conclusion, exhibiting a marked dependence of $\mu_{\mathrm{h}}$ on the side chain.

Acknowledgments. The authors wish to thank Professor Hiroshi Fujita for his valuable comments on this manuscript.

\section{REFERENCES}

1. A. Wada, in "Polyamino Acids, Polypeptides, and Proteins," M. A. Stahmann, Ed., Univ. Wisconsin Press, Madison, 1962, p 131.

2. A. Wada, in "Poly- $\alpha$-Amino Acids," G. D. Fasman, Ed., Marcel Dekker, New York, 1967, Chapter 9.

3. A. Wada, Bull. Chem. Soc., Jpn., 33, 822 (1960).

4. A. Wada, J. Chem. Phys., 31, 495 (1959).

5. M. Sharp, J. Chem. Soc., A, 1596 (1970).

6. E. H. Erenrich and H. A. Scheraga, Macromolecules, 5, 746 (1972).

7. G. D. Fasman, in "Polyamino Acids, Polypeptides, and Proteins," M. A. Stahmann, Ed., Univ. Wisconsin Press, Madison, 1962, p 221.

8. J. R. Parrish, Jr. and E. R. Blout, Biopolymers, 11, 1001 (1972).

9. A. Nakajima and M. Murakami, Biopolymers, 11, 1295 (1972).

10. A. Shoji and T. Kawai, Kobunshi Kagaku (Chem. High Polymers), 28, 805, 809 (1971).

11. W. B. Gratzer and P. Doty, J. Am. Chem. Soc., 85, 1193 (1963).

12. H. E. Auer and P. Doty, Biochemistry, 5, 1708, 1716 (1966).

13. R. T. Ingwall, H. A. Scheraga, N. Lotan, A. Berger, and E. Katchalski, Biopolymers, 6, 331 (1968).

14. T. Iio and S. Takahashi, Bull. Inst. Chem. Res., Kyoto Univ., 49, 80 (1971).

15. T. Iio, Biopolymers, 10, 1583 (1971).

16. E. M. Bradbury, P. D. Cary, and C. Crane-
Robinson, Macromolecules, 5, 581 (1972).

17. E. R. Blout and R. H. Karlson, J. Am. Chem. Soc., 78, 941 (1956).

18. K. Nakagawa, N. Nishioka, A. Teramoto, and H. Fujita, Polym. J., 4, 332 (1973).

19. N. Nishioka, A. Teramoto, and H. Fujita, Polym. J., 8, 121 (1976).

20. T. Matsumoto, N. Nishioka, A. Teramoto, and H. Fujita, Macromolecules, 7, 824 (1974).

21. I. Omura, A. Teramoto, and H. Fujita, Macromolecules, 8, 284 (1975).

22. A. J. Bur, J. Chem. Phys., 52, 3813 (1970).

23. J. Y. Cassim and E. W. Taylor, Biophys. J., 5, 553, 573 (1965).

24. J.S. Franzen, J. B. Harry, and C. Bobik, Biopolymers, 5, 193 (1967).

25. T. Matsumoto and A. Teramoto, Biopolymers, 13, 1347 (1974).

26. P. Urnes and P. Doty, Adv. Protein Chem., 16, 401 (1961).

27. A. Wada, "Biopolymers (Seitai-Kobunshi)," Iwanami, Tokyo.

28. J. Applequist and T. G. Mahr, J. Am. Chem. Soc., 88, 5419 (1966).

29. T. Norisuye, Thesis, Osaka University, 1973.

30. A. Teramoto and H. Fujita, Adv. Polym. Sci., 18, 65 (1975).

31. A. Wada, J. Polym. Sci., 45, 145 (1960).

32. E. Marchal, C. Hornick, and H. Benoit, $J$. Chim. Phys. Physicochem. Biol., 64, 514 (1967).

33. E. Marchal and J. Marchal, J. Chim. Phys. Physicochem. Biol., 64, 1607 (1967).

34. H. Block, E. F. Hayes, and A. M. North, Trans. Faraday Soc., 66, 1095 (1970).

35. A. Wada and H. Kihara, Polym. J., 3, 482 (1972).

36. S. Saruta and Y. Einaga, unpublished data.

37. M. Tsuboi, J. Polym. Sci., 59, 139 (1962).

38. E. M. Bradbury, B. G. Carpenter, C. CraneRobinson, and H. Goldman, Macromolecules, 4, 557 (1971). 